\title{
Association of Angiotensin I Converting Enzyme Insertion/287 bp Deletion Polymorphisms and Proliferative Prostatic Diseases among Lebanese Men
}

\author{
Asmahan A. El Ezzi, ${ }^{1,2}$ Jordan M. Clawson, ${ }^{3}$ Mohammed A. El-Saidi, ${ }^{4}$ Wissam R. Zaidan, ${ }^{1}$ \\ Abigail Kovash, ${ }^{3}$ Jeremy Orellana, ${ }^{3}$ AnnaKarina Thornock, ${ }^{3}$ and Ruhul H. Kuddus $\mathbb{D}^{3}$ \\ ${ }^{1}$ Radioimmunoassay Laboratory, Lebanese Atomic Energy Commission, Beirut, Lebanon \\ ${ }^{2}$ Department of Chemistry and Biochemistry, Lebanese University, Hadath, Lebanon \\ ${ }^{3}$ Department of Biology, Utah Valley University, Orem, UT, USA \\ ${ }^{4}$ Department of Strategic Management and Operations, Utah Valley University, Orem, UT, USA
}

Correspondence should be addressed to Ruhul H. Kuddus; ruhul.kuddus@uvu.edu

Received 20 November 2019; Revised 7 January 2020; Accepted 9 January 2020; Published 7 February 2020

Academic Editor: Cristina Magi-Galluzzi

Copyright (C) 2020 Asmahan A. El Ezzi et al. This is an open access article distributed under the Creative Commons Attribution License, which permits unrestricted use, distribution, and reproduction in any medium, provided the original work is properly cited.

\begin{abstract}
Background. Angiotensin I converting enzyme (ACE) insertion (I) and 287 bp Alu repeat DNA fragment deletion (D) polymorphisms have been indicated in various cancers. Here, we investigated I/D polymorphisms in prostate cancer (PCa) and benign prostate hyperplasia (BPH) among Lebanese men. Methods. Blood DNA extracted from 69 control subjects, 69 subjects with clinically confirmed PCa, and 69 subjects with clinical $\mathrm{BPH}$, all the subjects were aged 50 years or older, was subjected to the polymerase chain reaction. The PCR products were resolved in polyacrylamide gels to determine II, ID, and DD genotypes. The odds ratios (OR), 95\% confidence intervals (CI), and $p$ values of the allele frequencies and genotype ratios were calculated for establishing possible association of the alleles and/or genotypes and PCa and/or BPH. Results. The proportions of II, ID, and DD genotypes were significantly different from Hardy-Weinberg equilibrium for BPH and PCa groups (but not the control group), mostly due to overabundance of the ID genotypes. There was no significant difference in the I and D allele frequencies between the control groups and the affected groups. The ratio of (DD + ID)/II is significantly lower among the control group compared to the $\mathrm{BPH}$ group $(\mathrm{RR}=8.92, p=0.042)$, and the ratio of $\mathrm{ID} /(\mathrm{DD}+\mathrm{II})$ is significantly lower among the control group compared to the affected groups $(\mathrm{RR}=1.99, p=0.021)$. Conclusions. Our data indicate that the $\mathrm{D}$ allele of the I/D polymorphisms of the ACE gene is associated with increased risk of BPH, and the ID genotype is a risk factor for both BPH and PCa among Lebanese males.
\end{abstract}

\section{Introduction}

Prostate cancer (PCa) is the second most commonly diagnosed cancer among men worldwide and is the second leading cause of cancer death for men. In 2019, 174,650 new cases of PCa was diagnosed in the United States and the disease claimed the lives of 31,620 men in the United States that year [1]. Benign prostatic hyperplasia (BPH) is a noncancerous enlargement of the prostate gland that can occur as men age. In the United States, BPH affects nearly $70 \%$ of men between the ages of 60 and 69 and over $80 \%$ of men 70 years and older [2]. Both diseases appear to run in families and carry many of the same risk factors, including genetic and lifestyle factors [3]. Identifying genetic variations associated with prostatic diseases common in $\mathrm{PCa}$ and $\mathrm{BPH}$ may prove helpful in early diagnosis and treatment of $\mathrm{PCa}$, given that $\mathrm{PCa}$ is a deadly disease and often difficult to diagnose early, whereas $\mathrm{BPH}$ is a relatively benign disease, but it displays some diagnostic characteristics at the early phases of the disease.

The human angiotensin I converting enzyme (ACE) gene encodes an enzyme that catalyzes the processing of 
angiotensin I to angiotensin II and angiotensin (1-7) to angiotensin (1-5) [4]. Angiotensin II is further processed by another enzyme, angiotensin converting enzyme 2 (ACE2) to angiotensin (1-7) [5]. Angiotensin II is a potent vasopressor and aldosterone-stimulating peptide involved in blood pressure control and fluid-electrolyte balance [4]. Angiotensin (1-7) is a potent vasoconstrictor and an effector component of angiotensin II, while angiotensin (1-5) stimulates secretion of atrial natriuretic peptide (ANP) $[5,6]$. Overall, ACE plays a key role in the renin-angiotensin system by regulating fluid volume and controlling blood pressure. The ACE gene is located on chromosome 17 (17q23.3), and it has a 287 bp Alu repeat element insertion/ deletion (I/D) polymorphism in intron 16. The primary transcript of the gene is differentially spliced, and different versions of the mature mRNAs are translated to synthesize various isoforms of the enzyme; of them, one isoform is adequately expressed in the testis [4].

Given that ACE plays a key role in the renin-angiotensin system that regulates fluid volume and controls blood pressure, it is highly likely that I/D polymorphism of the ACE gene could have diverse physiological consequences. Indeed, the I and D alleles of the ACE gene have been associated with an increased risk for many diseases [7-12]. Uemura et al. [10] observed a statistically significant association of the $\mathrm{D}$ allele and high systolic and diastolic blood pressure in the Japanese population and obesity, hyperlipidemia, hypertension, and diabetes mellitus more prevalent among the ID and DD genotypes, compared to the II genotype. In another study involving a Brazilian population, no direct association of I/D polymorphism of the ACE gene and G8790A polymorphism of the ACE2 gene and systemic arterial hypertension was observed although significant association of the combination of the DD genotype and GG genotype with systemic arterial hypertension was observed [11]. A study in southeast Turkey indicated that women with DD or ID genotypes had a $72 \%$ increased risk of idiopathic recurrent pregnancy loss [12], while another study in northern Iran found the DD genotype to be more prevalent among women who have experienced recurrent pregnancy loss [13]. Additionally, the I/D polymorphism has been found to be associated with Alzheimer's disease; however, both the I allele [14, 15] and the D allele [16] have been found to be associated with an increased risk of developing the disease. Other studies have found the I/D polymorphism to be associated with various cancers. For example, one study observed an association of the D allele with a 3-fold increased risk for glioma in an Algerian population [17], while a Polish study found the DD genotype to be associated with a 2-fold increased risk for multiple myeloma [18]. The I/D polymorphisms of the ACE gene have also been implicated in prostate cancer and breast cancer (reviewed in [19]). In the present study, we examined the association of the $\mathrm{I} / \mathrm{D}$ polymorphism in the ACE gene and the risk of $\mathrm{PCa}$ and $\mathrm{BPH}$ among Lebanese men.

\section{Materials and Methods}

2.1. Subjects. All the subjects involved in this study were volunteer participants of prostate disorder screening campaigns organized by Prof. El Ezzi in collaboration with several hospitals/medical centers in Lebanon. An informed consent form to participate in the prostate-specific antigen (PSA) screening and associated investigative activities, including blood donation, extraction of DNA from blood cells, usage of DNA for genetic analysis, and use of the genetic data for research and publishing, was obtained from each subject in accordance with the ethical standards of the 1975 Declaration of Helsinki. The procedures and guidelines of the Institutional Review Board (IRB) of Utah Valley University were also followed (IRB approval \#00614). Each participant was evaluated for prostate health by measuring the serum total PSA (PSA-T) level followed by a digital rectal examination (DRE) if necessary. A PSA assay kit obtained from Immunotech (Marseille, France) was used to quantify the PSA-T level. For the subjects with a PSA-T level in the gray zone (i.e., between 4 and $10 \mathrm{ng} / \mathrm{ml}$ ), a free PSA test (PSA-F) was conducted and the PSA F/T ratio was determined to help differentiate between BPH and PCa. In addition, the International Prostate Symptom Score (IPSS) value was determined, and if necessary, a transrectal ultrasonography was conducted for appropriate cases. The subjects were considered control subjects if they had a normal level of PSA for two consecutive years, had a normal IPSS score, and a normal DRE at the time of sampling. The number of subjects with confirmed PCa was 69. Accordingly, 69 subjects with $\mathrm{BPH}$ and 69 control subjects were considered for the present study, yielding a total of 207 participants.

2.2. Molecular Methods. DNA was extracted from freshly collected whole blood samples using QiaAmp DNA Blood Mini Kit (Qiagen, Milan, Italy). DNA was quantified, and quality of DNA was assayed using a UV spectrometer. A fragment of the ACE gene flanking the I/D polymorphism was amplified by polymerase chain reaction (PCR) using the primers $5^{\prime}$-CTGGAGACCACTCCCATCCTTTCT-3' and 5'-GATGTGGCCATCTTCGTCAGAT-3' [9]. The PCR mixture $(15 \mu \mathrm{l})$ contained $1 \mathrm{x}$ reaction buffer containing 0.75 unit of Taq DNA polymerase (Qiagen, Germantown MD), 10 picomoles of the two primers, and $10 \mathrm{ng}$ of template DNA. The negative control PCR conducted simultaneously lacked any template DNA. The reactions were set in a UVdecontaminated Class II A2 biosafety cabinet (equipped with high efficiency particulate air filter) using a dedicated set of pipettes to avoid cross contamination. A GeneAmp 2700 thermocycler (Applied Biosystems, Carlsbad, CA) was used for PCR amplification. The thermocycler was programed as follows: $94^{\circ} \mathrm{C}$ for 5 minutes (one cycle), $94^{\circ} \mathrm{C}$ for $45 \mathrm{sec}, 58^{\circ} \mathrm{C}$ for $45 \mathrm{sec}$, and $72^{\circ} \mathrm{C}$ for $45 \mathrm{sec}(35 \mathrm{cycles}) ; 72^{\circ} \mathrm{C}$ for 5 minutes (one cycle); and soak at $4^{\circ} \mathrm{C}$. Amplified DNA was resolved in $6 \%$ polyacrylamide gels for about 90 minutes at 80 volts using $0.5 \mathrm{x}$ Tris-Borate-EDTA buffer as the electrolyte. The gels were stained for 20 minutes in ethidium bromide $(0.5 \mu \mathrm{g} / \mathrm{ml}$ in $0.5 \mathrm{x}$ Tris-borate-EDTA buffer $)$. The DNA bands were visualized on a UV transilluminator and then documented using a digital camera. The insertion (I) allele generated a 490 bp DNA fragment, while the deletion 
allele (D) generated a $290 \mathrm{bp}$ DNA fragment with the primer set used.

2.3. Statistical Analysis. The frequencies of the ACE gene I/D genotypes (II, ID, and DD) of the three samples in conjunction with Hardy-Weinberg (H-W) equilibrium were used to perform the $\chi^{2}$ goodness-of-fit. The null hypothesis that the genotypes of the three populations are in $\mathrm{H}-\mathrm{W}$ equilibrium were rejected at the 0.05 level of significance if the calculated $\chi^{2}$ test statistic produced a $p$ value smaller than 0.05 . Given the possibility of three genotypes (II, ID, and DD) and two alleles (I and D), the number of degrees of freedom was one. Association of the polymorphic genotypes with $\mathrm{PCa}$ and $\mathrm{BPH}$ was evaluated by calculating the odds ratio (OR) and the $95 \%$ confidence interval (CI). The relative risk (RR) for having a genotype in developing PCa or $\mathrm{BPH}$ along with the associated $95 \% \mathrm{CI}$ was also calculated. For all statistical tests conducted, a $p$ value less than 0.05 was considered significant. The OR, RR, 95\% CI, $p$ value, and the difference of the mean age of the control group and the affected groups were calculated using MedCalc Statistical Software for Biomedical Research (MedCalc Software, Acacialaan 22, B-8400 Ostend, Belgium).

\section{Results}

This study included 69 cases of PCa (mean age $66.4 \pm 8.5$ years), 69 subjects with confirmed $\mathrm{BPH}$ (mean age $69.1 \pm 8.4$ years), and 69 control subjects with no known prostate pathology (mean age $55.8 \pm 11.0$ years). The mean age of the control group is significantly different from that of PCa and BPH ( $p$ value $<0.001$ ). However, the mean age of the $\mathrm{PCa}$ and $\mathrm{BPH}$ groups is not significantly different $(p$ value $=0.062)$.

\subsection{Distribution of the Genotypes and Allele Frequencies.} The distribution of homozygous insertion (II), homozygous deletion (DD), and the heterozygous (ID) genotypes in the three samples is shown in Table 1. The distribution of the genotypes of the control group is in $\mathrm{H}-\mathrm{W}$ equilibrium. However, the ID genotype is overrepresented in both the $\mathrm{PCa}$ and $\mathrm{BPH}$ groups, making the distribution of the three genotypes significantly different from $\mathrm{H}-\mathrm{W}$ equilibrium for the PCa group $\left(\chi^{2}=5.61, p\right.$ value $\left.=0.018\right)$ and the BPH group $\left(\chi^{2}=17.62, p\right.$ value $\left.<0.001\right)$.

The frequency and the proportion of the I and D alleles among the control subjects and the PCa and $\mathrm{BPH}$ groups are shown in Table 2. There is no significant difference in the distribution of the I and $\mathrm{D}$ alleles between the control group and $\mathrm{PCa}$ group $(\mathrm{OR}=1.24,95 \% \mathrm{CI}=0.76-2.01, p$ value $=0.387$ ), between the control group and $\mathrm{BPH}$ group $(\mathrm{OR}=1.0,95 \% \mathrm{CI}=0.16-1.63, p$ value $=1.00)$, or between the control group and the combined affected groups $(\mathrm{OR}=1.11,95 \% \mathrm{CI}=0.073-1.70, p$ value $=0.616)$.

3.2. Genotype Frequencies and Genotypic Ratios. The frequency of II, DD, and ID genotypes for the control group and the $\mathrm{PCa}$ and $\mathrm{BPH}$ groups along with the $\mathrm{OR}, \mathrm{RR}$ of $\mathrm{PCa}$ or $\mathrm{BPH}, 95 \% \mathrm{CI}$, and the $p$ values are shown in Table 3. There is no significant difference in the ratios $\mathrm{DD} / \mathrm{II}, \mathrm{DD} / \mathrm{ID}$, $(\mathrm{DD}+\mathrm{ID}) / \mathrm{II}$, (ID + II)/DD, or ID/(II + DD) for the control subjects and the subjects with PCa (Table 3). However, the ratio of (DD + ID)/II of the control group and subjects with $\mathrm{BPH}$ are significantly different $(\mathrm{OR}=8.92,95 \% \mathrm{CI}$ $1.08-73.37$, $p$ value $=0.042$ and the corresponding $R R=1.11$, $95 \%$ CI 1.02-1.22, $p$ value $=0.018$ ). The DD to II ratio for the control group is also significantly lower compared to subjects with $\mathrm{BPH}(\mathrm{OR}=5.93,95 \%$ CI $0.682-51.27, p$ val$\mathrm{ue}=0.106$; the corresponding $\mathrm{RR}=1.23,95 \% \mathrm{CI} 1.00-1.51, p$ value $=0.043$ ), indicating that the $\mathrm{D}$ allele is associated with increased risk of $\mathrm{BPH}$. In addition, the ID/(II + DD) ratio is significantly lower among the control subjects compared to the subjects with $\mathrm{BPH}(\mathrm{RR}=2.35,95 \% \mathrm{CI} 1.17-4.72, p$ value $=0.016$ and the corresponding $\mathrm{RR}=1.41,95 \% \mathrm{CI}$ $1.06-1.88, p$ value $=0.018)$, indicating that the ID genotype is a risk factor for $\mathrm{BPH}$. The $\mathrm{ID} /(\mathrm{II}+\mathrm{DD})$ ratio is also significantly lower among the control subjects compared to the affected subjects $(\mathrm{OR}=1.99,95 \% \mathrm{CI} 1.10-3.59, p$ val$\mathrm{ue}=0.021 ;$ and the corresponding $\mathrm{RR}=1.34,95 \% \mathrm{CI}$ $1.02-1.75, p$ value $=0.032$ ), again indicating that the ID genotype is potentially a risk factor for $\mathrm{PCa}$ and $\mathrm{BPH}$ subjects.

\section{Discussion}

Lebanon is a small country with a population of 6.1 million. In 2018, a total of 8809 new cases of cancers were diagnosed among the male population of the country. Prostate cancer was the most diagnosed cancer (17.1\% of all cancer cases) among males in that year, and overall, prostate cancer was the fourth most diagnosed cancer (behind breast, bladder, and lung cancers) in the country [20]. The age-standardized incidence rate of prostate cancer changed from 27.6 cases/ 100,000 in 2003 [21] to 39.2 cases/100,000 by 2008 indicating a $7.6 \%$ increase [22]. We were unable to find any published data on $\mathrm{BPH}$ incidence in Lebanon, but the incidence is expected to be high, given that BPH is an age-associated disease [2] and the relatively high life expectancy (78 years) of Lebanese men [23]. In this study, we examined the association of the I/D polymorphism with $\mathrm{PCa}$ and $\mathrm{BPH}$ among Lebanese men.

Our preliminary analyses showed no association of I/D polymorphism and PCa or BPH among Lebanese men [24]. However, a more critical analysis involving confirmed cases of PCa and BPH presented here indicated a positive association of the D allele with $\mathrm{BPH}$ and confirmed a lack of association between I/D polymorphism and the risk of PCa. However, our data indicate that the ID genotype is a risk factor for both PCa and $\mathrm{BPH}$. A previous study [25] indicated that the I allele is protective, while the D allele is associated with PCA, and the DD genotype is related to aggressive stage of $\mathrm{PCa}$ in the Han population of China. Another study in Iran indicated that subjects with II genotype have a higher PSA level than subjects with DD genotype [26]. The same study also indicated that II genotype is associated with $\mathrm{BPH}$ and the $\mathrm{D}$ allele is associated with $\mathrm{PCa}$ 
TABle 1: Allelic distribution of ACE gene among the control subjects $(n=69)$ and the subjects with BPH $(n=69)$ or PCa $(n=69)$.

\begin{tabular}{|c|c|c|c|c|}
\hline Groups & Observed frequency (II : ID : DD) & Expected frequency (II:ID : DD) & $\chi^{2}$ statistic & $p$ value \\
\hline Control & $8: 34: 27$ & $9.06: 31.88: 28.06$ & 0.304 & 0.581 \\
\hline $\mathrm{PCa}$ & $7: 43: 19$ & $11.77: 33.46: 23.77$ & 5.61 & $0.018^{*}$ \\
\hline $\mathrm{BPH}$ & $1: 48: 20$ & $9.06: 31.88: 28.06$ & 17.62 & $<0.001^{*}$ \\
\hline
\end{tabular}

*Significant at the 0.05 level of significance.

TABLE 2: The frequencies (and proportions) of the I and D alleles of the ACE gene among the controls and the subjects with PCa or BPH.

\begin{tabular}{|c|c|c|c|c|c|}
\hline Alleles & Control & Affected & OR & $95 \% \mathrm{CI}$ & $p$ values \\
\hline \multicolumn{6}{|c|}{ A. Control group versus PCa group } \\
\hline I & $50(0.36)$ & $57(0.41)$ & 1 & & \\
\hline $\mathrm{D}$ & $88(0.64)$ & $81(0.59)$ & 1.24 & $0.76-2.01$ & 0.387 \\
\hline \multicolumn{6}{|c|}{ B. Control group versus BPH group } \\
\hline I & $50(0.36)$ & $50(0.36)$ & 1 & & \\
\hline $\mathrm{D}$ & $88(0.64)$ & $88(0.64)$ & 1.00 & $0.61-1.63$ & 1.00 \\
\hline \multicolumn{6}{|c|}{ C. Control group versus the combined $P C a$ and $B P H$ groups } \\
\hline I & $50(0.36)$ & $107(0.39)$ & 1 & & \\
\hline $\mathrm{D}$ & $88(0.64)$ & $169(0.61)$ & 1.11 & $0.73-1.70$ & 0.616 \\
\hline
\end{tabular}

TABLE 3: The frequencies of the genotypes II, ID, and DD of the control and the subjects with PCa or BPH.

\begin{tabular}{|c|c|c|c|c|c|c|c|c|}
\hline Allele & Control & Affected & OR & $95 \% \mathrm{CI}$ & $p$ value & $\mathrm{RR}$ & $95 \% \mathrm{CI}$ & $p$ value \\
\hline \multicolumn{9}{|c|}{ A. Control group versus $P C a$ group } \\
\hline $\mathrm{DD} / \mathrm{II}$ & $27 / 8$ & $19 / 7$ & 0.80 & $0.25-2.60$ & 0.716 & 0.95 & $0.71-1.27$ & 0.719 \\
\hline $\mathrm{DD} / \mathrm{ID}$ & $27 / 34$ & $19 / 43$ & 0.56 & $0.27-1.17$ & 0.120 & 0.69 & $0.43-1.11$ & 0.124 \\
\hline$(\mathrm{DD}+\mathrm{ID}) / \mathrm{II}$ & $61 / 8$ & $62 / 7$ & 1.16 & $0.40-3.40$ & 0.785 & 1.02 & $0.90-1.14$ & 0.785 \\
\hline$(\mathrm{II}+\mathrm{ID}) / \mathrm{DD}$ & $42 / 27$ & $50 / 19$ & 1.69 & $0.83-3.46$ & 0.150 & 1.19 & $0.94-1.51$ & 0.152 \\
\hline $\mathrm{ID} /(\mathrm{DD}+\mathrm{II})$ & $34 / 35$ & $43 / 26$ & 1.70 & $0.86-3.35$ & 0.124 & 1.26 & $0.94-1.71$ & 0.127 \\
\hline \multicolumn{9}{|c|}{ B. Control group versus $B P H$ group } \\
\hline $\mathrm{DD} / \mathrm{II}$ & $27 / 8$ & $20 / 1$ & 5.93 & $0.68-51.27$ & 0.106 & 1.23 & $1.00-1.51$ & $0.043^{*}$ \\
\hline $\mathrm{DD} / \mathrm{ID}$ & $27 / 34$ & $20 / 48$ & 0.52 & $0.25-1.08$ & 0.082 & 0.66 & $0.42-1.06$ & 0.084 \\
\hline$(\mathrm{DD}+\mathrm{ID}) / \mathrm{II}$ & $61 / 8$ & $68 / 1$ & 8.92 & $1.08-73.37$ & $0.042^{*}$ & 1.11 & $1.02-1.22$ & $0.018^{*}$ \\
\hline$(\mathrm{II}+\mathrm{ID}) / \mathrm{DD}$ & $42 / 27$ & $49 / 20$ & 1.58 & $0.77-3.20$ & 0.210 & 1.17 & $0.92-1.49$ & 0.212 \\
\hline $\mathrm{ID} /(\mathrm{DD}+\mathrm{II})$ & $34 / 35$ & $48 / 21$ & 2.35 & $1.17-4.72$ & $0.016^{*}$ & 1.41 & $1.06-1.88$ & $0.018^{*}$ \\
\hline \multicolumn{9}{|c|}{ C. Control group versus the combined PCa and BPH (affected) groups } \\
\hline $\mathrm{DD} / \mathrm{II}$ & $27 / 8$ & $39 / 8$ & 1.44 & $0.48-4.32$ & 0.512 & 1.08 & $0.86-1.34$ & 0.520 \\
\hline $\mathrm{DD} / \mathrm{ID}$ & $27 / 34$ & $39 / 91$ & 0.54 & $0.29-1.01$ & 0.055 & 0.68 & $0.46-0.99$ & $0.048^{*}$ \\
\hline$(\mathrm{DD}+\mathrm{ID}) / \mathrm{II}$ & $61 / 8$ & $130 / 8$ & 2.13 & $0.76-5.95$ & 0.148 & 1.07 & $0.97-1.17$ & 0.190 \\
\hline$(\mathrm{II}+\mathrm{ID}) / \mathrm{DD}$ & $42 / 27$ & $99 / 39$ & 1.63 & $0.88-3.00$ & 0.115 & 1.18 & $0.95-1.46$ & 0.136 \\
\hline $\mathrm{ID} /(\mathrm{DD}+\mathrm{II})$ & $34 / 35$ & $91 / 47$ & 1.99 & $1.10-3.59$ & $0.021^{*}$ & 1.34 & $1.02-1.75$ & $0.032^{*}$ \\
\hline
\end{tabular}

* Significant at the 0.05 level of significance.

risk, but the associations were not statistically significant [26]. A study in the Mexican population found the D allele to be associated with increased risk of both PCa and BPH [27]. A study in Turkey also found the D allele associated with increased risk with PCa, and the DD genotype was found to contain a higher level of PSA-T [9]. A metanalysis involving 35 published studies indicated lack of association of I/D alleles or genotypes and risk of PCa or any other cancers although the I allele and II genotype were found to be associated with increased cancer risk among Caucasians [8]. A more recent metanalysis analyzing multiple study found no association of I/D polymorphism and PCa risk overall and among the Caucasian males in particular although the study found the $\mathrm{D}$ allele and the DD genotype associated with increased risk of PCa among the Asian and Latino males
[28]. Similar inconsistencies were observed when the association of the I/D polymorphism and other cancers such as breast cancer [29, 30], lung cancer [31, 32], and colorectal cancer $[33,34]$ was investigated.

The above discussion indicates that although the $\mathrm{D}$ allele appears to be a risk factor for increased cancer risk $[9,25-28]$, the I/D polymorphism is generally not a risk factor for $\mathrm{BPH}, \mathrm{PCa}$, or other cancers, and one of the alleles or genotypes can be associated with increased risk of cancer in certain ethnic groups. Many different factors including a possible polygenic basis for the diseases, variability in penetrance, and the environmental conditions different ethnic and racial groups encounter [35] may contribute to such variable clinical outcomes. If multiple genes were involved in $\mathrm{PCa}, \mathrm{BPH}$, or any cancers and if some of the genes 
were polymorphic, a subject might have some protective and some risk-bearing alleles of the genes [36], adding additional layers of influences on the phenotypic outcomes. A system biology approach such as the genome-wide association studies (GWAS) is currently being applied to address the issue $[37,38]$. However, identification of important genetic polymorphisms relevant to disease risks of different ethnic groups would remain useful given that genetic polymorphisms are extremely common.

\section{Conclusion}

The present data indicates that the $\mathrm{D}$ allele of the I/D polymorphism is associated with increased risk of $\mathrm{BPH}$ and the ID genotype is associated with increased risk of $\mathrm{BPH}$ and PCa among Lebanese males.

5.1. Limitations. The small population of Lebanon and the smaller number of males volunteered to participate in the study contributed to some limitations of the present study. The overall sample sizes of the control and the PCa and $\mathrm{BPH}$ groups are relatively small, and although all participants of the study were 50 or older, the difference in the mean age of the control group and the affected groups is statistically significant.

\section{Data Availability}

The detailed genotyping data of the patients are available from the corresponding author and only to be made available to researchers who meet the criteria for access.

\section{Conflicts of Interest}

The authors declare that there are no conflicts of interest regarding the publication of this work.

\section{Acknowledgments}

The authors are grateful to the Lebanese Urology Society for aiding the prostatic disease campaigns, Ms. Hassana Shouman of LAEC for data entry and contacting volunteers, and Vladyslav Boyko for assistance in data processing. Professors El Ezzi and Kuddus are the supervising coauthors. This work was partly supported by a grant from the National Council for Scientific Research in Lebanon and the Lebanese Atomic Energy Commission (LAEC) to AEE and a Utah Valley University SAC grant to JMC.

\section{References}

[1] ACS (American Cancer Society), Key Statistics for Prostate Cancer, and Causes, Risk Factors and Prevention, American Cancer Society, New York, NY, USA, 2016, http://www. Cancer.org/cancer/prostatecancer/detailguide/.

[2] J. T. Wei, E. Calhoun, and S. J. Jacobsen, "Urologic diseases in America project: benign prostatic hyperplasia," Journal of Urology, vol. 173, no. 4, pp. 1256-1261, 2005.
[3] X. Dai, X. Fang, Y. Ma, and J. Xianyu, "Benign prostatic hyperplasia and the risk of prostate cancer and bladder cancer," Medicine, vol. 95, no. 18, Article ID e3493, 2016.

[4] "Gene cards human gene database," 2019, https://www. genecards.org/cgi-bin/carddisp.pl?gene=ACE\&keywords $=$ The, human, angiotensin, converting,enzyme, 1 .

[5] M. C. Chappell, "Biochemical evaluation of the renin-angiotensin system: the good, bad, and absolute?" American Journal of Physiology-Heart and Circulatory Physiology, vol. 310, no. 2, pp. H137-H152, 2016.

[6] L. Yu, K. Yuan, H. T. A. Phuong, B. M. Park, and S. H. Kim, "Angiotensin-(1-5), an active mediator of renin-angiotensin system, stimulates ANP secretion via Mas receptor," Peptides, vol. 86, pp. 33-41, 2016.

[7] R. M. Ned, A. Yesupriya, G. Imperatore et al., "The ACE I/D polymorphism in US adults: limited evidence of association with hypertension-related traits and sex-specific effects by race/ethnicity," American Journal of Hypertension, vol. 25, no. 2, pp. 209-215, 2012.

[8] K. Zhang, D. Cheng, L. Yi, H. Shi, and G. Zhen, "Association between angiotensin I-converting enzyme gene polymorphism and susceptibility to cancer: a meta analysis," International Journal of Clinical and Experimental Pathology, vol. 7, no. 9, pp. 6291-6300, 2014.

[9] B. Yigit, N. Bozkurt, F. Narter, H. Yilmaz, E. Yucebas, and T. Isbir, "Effects of ACE I/D polymorphism on prostate cancer risk, tumor grade and metastatis," Anticancer Research, vol. 27, no. 2, pp. 933-936, 2007.

[10] K. Uemura, J. Nakura, K. Kohara, and T. Miki, "Association of ACE I/D polymorphism with cardiovascular risk factors," Human Genetics, vol. 107, no. 3, pp. 239-242, 2000.

[11] D. S. Pinheiro, R. S. Santos, P. C. B. V. Jardim et al., "The combination of ACE I/D and ACE2 G8790A polymorphisms revels susceptibility to hypertension: a genetic association study in Brazilian patients," PLoS One, vol. 14, no. 8, Article ID e0221248, 2019.

[12] E. Gumus, "The powerful association of angiotensin-converting enzyme insertion/deletion polymorphism and idiopathic recurrent pregnancy loss," Ginekologia Polska, vol. 89, no. 10 , pp. $573-576,2018$.

[13] S. Fazelnia, T. Farazmandfar, and S. M. B. Hashemi-Soteh, "Significant correlation of angiotensin converting enzyme and glycoprotein IIIa genes polymorphisms with unexplained recurrent pregnancy loss in north of Iran," International Journal of Reproductive BioMedicine, vol. 14, no. 5, pp. 323328, 2016.

[14] Y. Yuan, J.-H. Piao, K. Ma, and N. Lu, “Angiotensin-converting enzyme gene insertion-deletion polymorphism is a risk marker for Alzheimer's disease in a Chinese population: a meta-analysis of case-control studies," Journal of Neural Transmission, vol. 122, no. 8, pp. 1105-1113, 2015.

[15] O. M. Hassanin, M. Moustafa, and T. M. El Masry, "Association of insertion-deletion polymorphism of ACE gene and Alzheimer's disease in Egyptian patients," Egyptian Journal of Medical Human Genetics, vol. 15, no. 4, pp. 355-360, 2014.

[16] N. Fekih-Mrissa, I. Bedoui, A. Sayeh et al., "Association between an angiotensin-converting enzyme gene polymorphism and Alzheimer's disease in a Tunisian population," Annals of General Psychiatry, vol. 16, no. 1, p. 41, 2017.

[17] I. H. Benenemissi, K. Sifi, L. K. Sahli, O. Semmam, N. Abadi, and D. Satta, "Angiotensin-converting enzyme insertion/ deletion gene polymorphisms and the risk of glioma in an Algerian population," Pan African Medical Journal, vol. 32, p. 197, 2019. 
[18] S. Zmorzynski, A. Szudy-Szczyrek, S. Popek-Marciniec et al., "ACE insertion/deletion polymorphism (rs4646994) is associated with the increased risk of multiple myeloma," Frontiers in Oncology, vol. 9, p. 44, 2019.

[19] R. Ruiter, L. E. Visser, C. M. Van Duijn, and B. H. Stricker, "The ACE insertion/deletion polymorphism and risk of cancer, a review and meta-analysis of the literature," Current Cancer Drug Targets, vol. 11, no. 4, pp. 421-430, 2011.

[20] International Agency for Research on Cancer, The Global Cancer Observatory (International Agency for Research on Cancer, the World Health organization), International Agency for Research on Cancer, Lyon, France, 2019, http://gco.iarc.fr/ today/data/factsheets/populations/422-lebanon-fact-sheets. pdf.

[21] A. Shamseddine and K. M. Musallam, "Cancer epidemiology in Lebanon," Middle East Journal of Cancer, vol. 1, no. 1, pp. 41-44, 2010.

[22] A. Shamseddine, A. Saleh, M. Charafeddine et al., "Cancer trends in Lebanon: a review of incidence rates for the period of 2003-2008 and projections until 2018," Population Health Metrics, vol. 12, p. 4, 2014.

[23] World Health Organization, Cancer Country Profile, World Health Organization, Geneva, Switzerland, 2019, https:// www.who.int/cancer/country-profiles/lbn_en.pdf.

[24] J. Clawson, A. Kovash, J. Orellana et al., Association of Angiotensin Converting Enzyme Insertion/287 bp Deletion Polymorphisms and Proliferative Prostatic Diseases Among Lebanese Men, National Conference for Undergraduate Research, Kennesaw, GA, USA, 2019.

[25] X. Wang, S. Wang, Y.-W. Lin et al., "Angiotensin-converting enzyme insertion/deletion polymorphism and the risk of prostate cancer in the Han population of China," Medical Oncology, vol. 29, no. 3, pp. 1964-1971, 2012.

[26] M. Hasanzad, M. Samzadeh, S. H. Jamaldini, A. A. Haghdoost, M. Afshari, and S. A. M. Ziaei, "Association of angiotensin I converting enzyme polymorphism as genetic risk factor in benign prostatic hyperplasia and prostate cancer," Genetic Testing and Molecular Biomarkers, vol. 16, no. 7, pp. 770-774, 2012.

[27] D. E. Sierra, C. J. Sánchez, G. R. C. Rosales et al., “Angiotensin-converting enzyme insertion/deletion and angiotensin type 1 receptor A1166C polymorphisms as genetic risk factors in benign prostatic hyperplasia and prostate cancer," Journal of the Renin-Angiotensin-Aldosterone System, vol. 10, no. 4, pp. 241-246, 2009.

[28] Z. Wang-Yang, H. Y. Li, Z. P. Jiang, and T. B. Zhou, "Relationship between angiotensin-converting enzyme insertion/ deletion gene polymorphism and prostate cancer susceptibility," Journal of Cancer Research and Therapeutics, vol. 14, no. Supplement, pp. S375-S380, 2018.

[29] M. Moghimi, S. Kargar, M. A. Jafari et al., "Angiotensin converting enzyme insertion/deletion polymorphism is associated with breast cancer risk: a meta-analysis," Asian Pacific Journal of Cancer Prevention, vol. 19, no. 11, pp. 3225-3231, 2018.

[30] X.-L. Li, Z.-J. Zheng, and H.-O. Qu, "Lack of association of angiotensin-converting enzyme insertion/deletion polymorphism with breast cancer: an update meta-analysis based on 10405 subjects," Journal of the Renin-Angiotensin-Aldosterone System, vol. 16, no. 4, pp. 1095-1100, 2015.

[31] N. Wang, D. Yang, B. Ji, and J. Li, "Angiotensin-converting enzyme insertion/deletion gene polymorphism and lung cancer risk: a meta-analysis," Journal of the Renin-Angiotensin-Aldosterone System, vol. 16, no. 1, pp. 189-194, 2015.
[32] S. D. Pavlić, S. Ristić, V. Flego, M. Kapović, and A. R. Badovinac, "Angiotensin-converting enzyme insertion/ deletion gene polymorphism in lung cancer patients," Genetic Testing and Molecular Biomarkers, vol. 16, no. 7, pp. 722-725, 2012.

[33] X. Zheng, G. Liu, G. Cui, M. Cheng, N. Zhang, and S. Hu, "Angiotensin-converting enzyme gene deletion polymorphism is associated with lymph node metastasis in colorectal cancer patients in a Chinese population," Medical Science Monitor, vol. 23, pp. 4926-4931, 2017.

[34] Y. Zhang, J. He, Y. Deng et al., "The insertion/deletion (I/D) polymorphism in the Angiotensin-converting enzyme gene and cancer risk: a meta-analysis," BMC Medical Genetics, vol. 12, p. 159, 2011.

[35] R. Konwar, N. Chattopadhyay, and H. K. Bid, "Genetic polymorphism and pathogenesis of benign prostatic hyperplasia," BJU International, vol. 102, pp. 536-544, 2008.

[36] A. Azzouzi, B. Cochand-Priollet, P. Mangin et al., "Impact of constitutional genetic variation in androgen/oestrogen-regulating genes on age-related changes in human prostate," European Journal of Endocrinology, vol. 147, pp. 479-484, 2002 .

[37] S. Benafif, Z. Kote-Jarai, and R. A. Eeles, "A review of prostate cancer genome-wide association studies (GWAS)," Cancer Epidemiology Biomarkers \& Prevention, vol. 27, no. 8, pp. 845-857, 2018.

[38] S. Farashi, T. Kryza, J. Clements, and J. Batra, "Post-GWAS in prostate cancer: from genetic association to biological contribution," Nature Reviews Cancer, vol. 19, no. 1, pp. 46-59, 2019. 